\title{
7. Climate change and the future of the liberalised electricity markets
}

\section{Guido Cervigni}

\subsection{INTRODUCTION}

As noted in Chapter 1, Section 1.10, the main driver of the expected evolution of electricity systems in industrialised countries is the objective to reduce emissions of the main greenhouse gases responsible for the increase in global mean temperature (global warming).

The Kyoto Protocol, an international agreement linked to the United Nations Framework Convention on Climate Change, sets binding targets for reducing greenhouse gas emissions for 37 industrialised countries and the European Community. The reductions amount to an average of 5 per cent over 1990 levels for the 2008-12 period.

In Europe, the Climate and Energy Package passed at the end of $2008^{1}$ set the 20-20-20 targets to be achieved by 2020: greenhouse gas emissions at least 20 per cent below 1990 levels, 20 per cent of energy consumption provided by renewable resources and a 20 per cent reduction of primary energy use against a baseline scenario.

Given that the deployment of renewables in electricity is more cost efficient than in transport and, to a lesser extent, heating, the burden of the total renewable energy target placed on the electricity sector will be greater. Against a 20 per cent renewable target for total energy, the production of electricity from renewable sources in Europe is expected to rise from 21 per cent in 2010 to 33 per cent in $2020 .^{2}$ Greenhouse gas emissions related to the power generation sector are expected to decrease by 3.4 per cent by 2030 compared with $2010 .^{3}$

Figure 7.1 illustrates the expected dynamics of renewable production in the biggest European countries. Wind and solar production, 5 per cent of the total in 2010, will account for about 16 per cent of the electricity generated in Europe in 2020. This will be delivered by a variety of support schemes implemented at national level, ${ }^{4}$ including: 


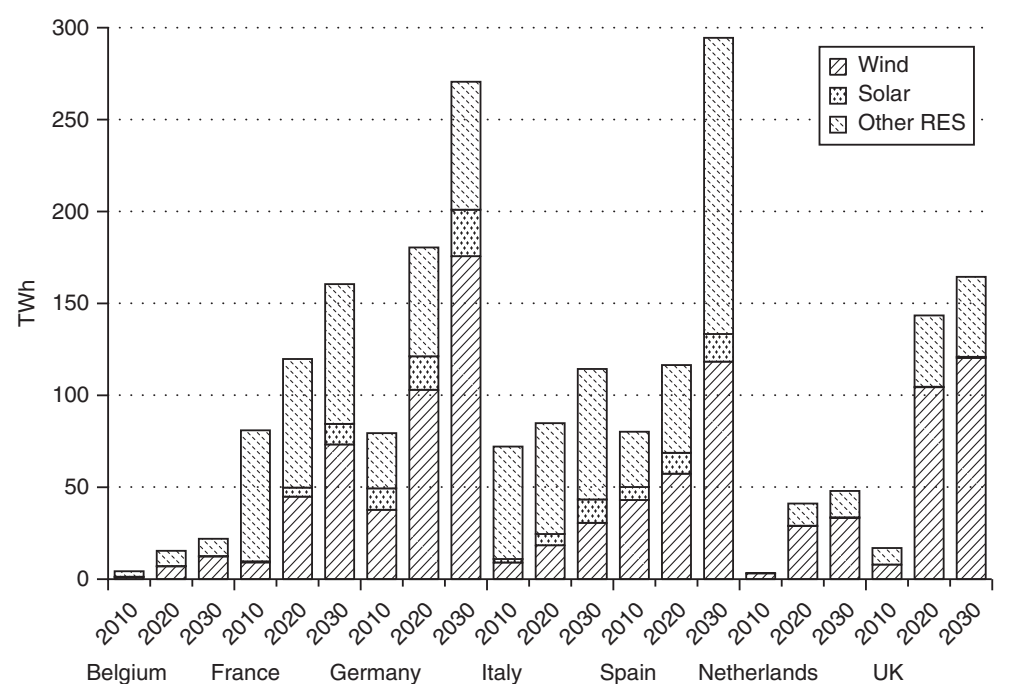

Sources: For year 2010: Eurostat, Energy Data. For years 2020 and 2030: European Commission, EU Energy Trends to 2030.

Figure 7.1 Expected dynamics of the share of solar and wind generation on total generation from renewable sources

- feed-in tariffs, which pay a regulated price for electricity produced from renewable sources irrespective of the market price for electricity;

- feed-in premiums, uplifts to electricity market prices paid for renewable production; compared with feed-in tariffs these place more risk on the renewable generator, which remains exposed to the volatility of the electricity market price;

- renewable obligations, an obligation to source a certain percentage of electricity supplies from renewable energy sources, typically placed on electricity retailers. The obligation is discharged by surrendering green certificates of renewable production issued by the renewable generators. A market for green certificates is then created, on which renewable generators obtain additional revenues by selling green certificates; and

- tendering systems for the selection of renewable generators admitted to the subsidy scheme - which can take several forms including a feed-in tariff and capacity payments. In this case the size of the subsidy is a by product of the auction process. 
A further source of support for renewable electricity generation is the European Union Emissions Trading System (ETS), a cap and trade system on $\mathrm{CO}_{2}$ emissions introduced in 2005 that covers industrial plants - including power plants over $20 \mathrm{MW}$, iron and steel plants, along with cement, glass, lime, brick, ceramics, and pulp and paper installations. In addition, aviation is being phased into the ETS, which currently covers almost half the EU's $\mathrm{CO}_{2}$ emissions. The scheme requires companies to surrender allowances equivalent to their level of $\mathrm{CO}_{2}$ emissions. A market in carbon allowances is then created, because companies can sell allowances if they cut their own emissions, or buy them if they have insufficient allowances to cover their emissions. The cost of the $\mathrm{CO}_{2}$ allowances adds to the variable cost of conventional thermal generators, and ultimately to the market price for electricity, which results in additional income for renewable generators that are exposed to the market price for electricity. ${ }^{5}$

Massive transmission investments will be needed in Europe in order to connect the expected $315 \mathrm{GW}$ of renewable capacity expected to be built by 2030. The European Commission has estimated that total investments in European-wide network infrastructures up to 2020 will amount to around $€ 200$ billion. ${ }^{6}$ The expansion of small-scale generation connected to the distribution grids may lead to power flows from the low-voltage to the medium-voltage grid. Managing bi-directional flows under security conditions will require investments in equipment and possibly significant organisational changes to distribution network operations. The European Commission estimates that by 2020 smart grid investments will reach about $€ 56$ billion. $^{7}$

Finally, electricity demand is expected to contribute to the achievement of sustainability objectives. Policy measures to reduce consumption are being implemented in most countries, and further benefits are expected from an increase in the demand response to prices. Enabling small consumers to adjust consumption to changes in spot prices will require massive investment and the development of a large body of new technical, commercial and organisational arrangements.

In Section 7.2 we assess the impact of the growing share of renewable electricity production on the optimal generating capacity mix. We also discuss the new risk allocation between generators and consumers resulting from politicisation of the development of renewable generation capacity. In Section 7.3 we analyse the impact of the growing share of intermittent generation capacity on the markets close to the time of delivery, when the market participants balance their positions and the system operator procures ancillary services. Finally, in Section 7.4 we discuss the possible implications of sustainability objectives on the electricity retail market. 


\subsection{WHOLESALE ELECTRICITY PRICES AND GENERATION CAPACITY DEVELOPMENT}

The recent wave of investment in renewable generation capacity has coincided with a slowdown in the growth of electricity demand brought about by the global economic crisis that began in 2009.8 The combined effects may have led to excess capacity in some countries such as Italy and Spain in Europe. The end of the nuclear programme in Germany, with the decommissioning of $17 \mathrm{GW}$ of generation capacity by 2020 , could mitigate the demand-reducing effect of the economic crisis.

The growing share of renewable capacity will affect the composition of the entire generation fleet in the long run. Figures 7.2 and 7.3 show total load and total load net of wind and solar power in Germany and the UK, respectively, in 2011 for the one thousand hours with the highest load during the year. The figures show that the production profile of renewable

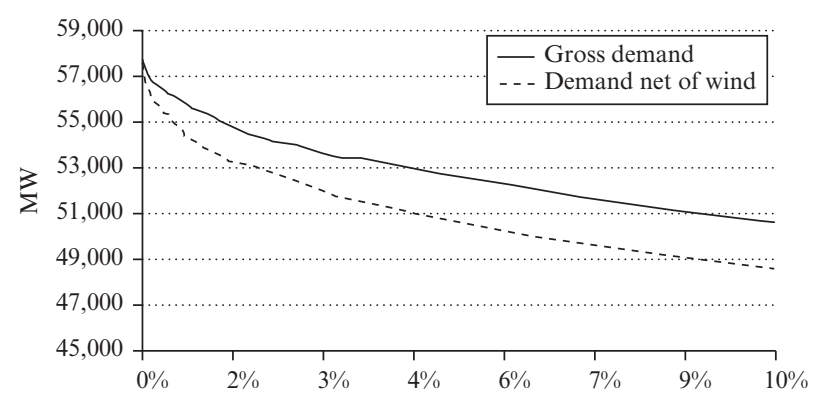

Figure 7.2 Total load and total load net of wind and solar generation in Germany

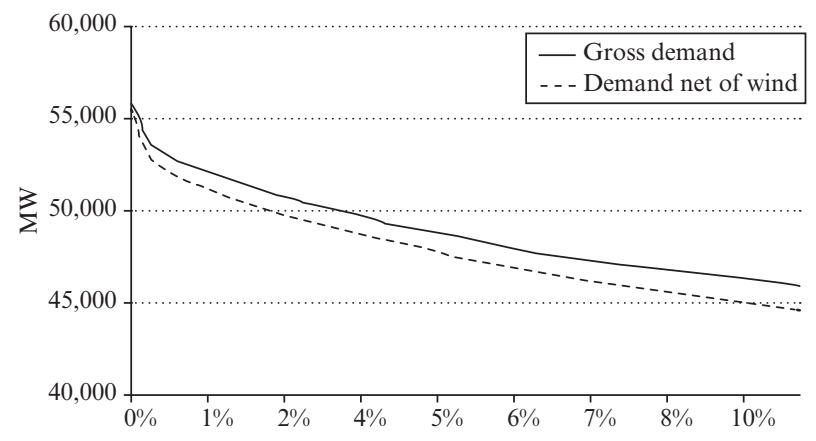

Figure 7.3 Total load and total load net of wind and solar generation in the $U K$ 


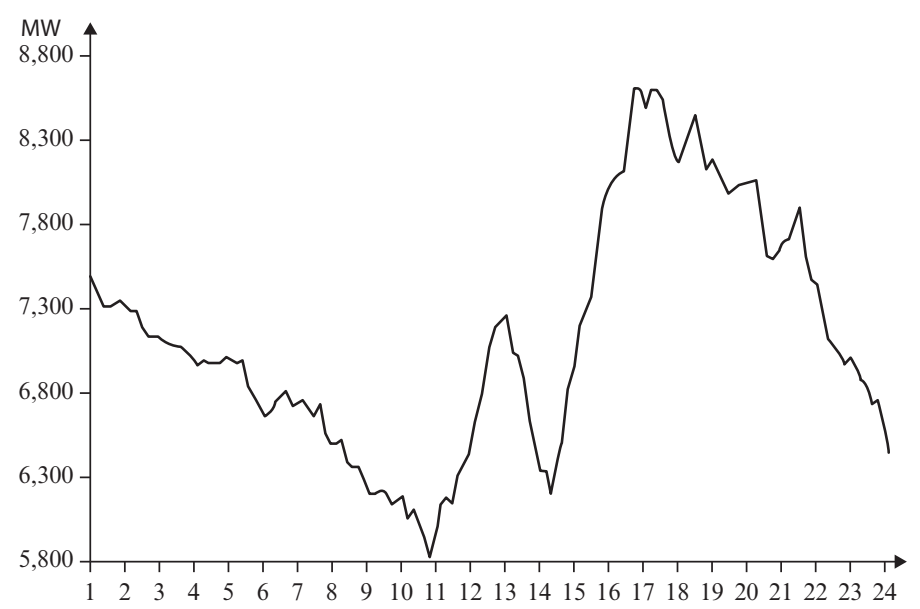

Source: Red Eléctrica de España.

Figure 7.4 Wind production in Spain, 30 March 2008

generators is such that the residual load that needs to be covered by thermal generators is peakier, that is, the proportion of residual load in peak hours is higher than the proportion of total load.

In addition wind production shows great variability. Figure 7.4 reports, for example, wind production in Spain on 30 March 2008. In three hours wind output increased by more than 2,000 MW, about 8 per cent of load.

Wind and solar production is intermittent and poorly predictable far in advance of real time. Figure 7.5 shows the prediction error of wind production in Germany at various times before the time of delivery. The predictions formulated the day before delivery - the traditional timeframe for thermal unit commitment decisions - are highly inaccurate compared with those taken 1-4 hours before real time. Since reliable information on the share of load covered by wind production only becomes available near the time of delivery, an increasing share of non-renewable generation capacity needs to be scheduled, and possibly committed, shortly before real time.

The available evidence suggests that, as the share of renewable generation increases, an efficient generation fleet will include a larger share of units capable of operating efficiently over a wide range of production levels, with fast start-up capabilities and high ramp rates. ${ }^{9}$ Other things being equal, average market prices should rise as a result of peaking units being the price makers for a larger number of hours.

Greater renewable production is also expected to result in larger power 


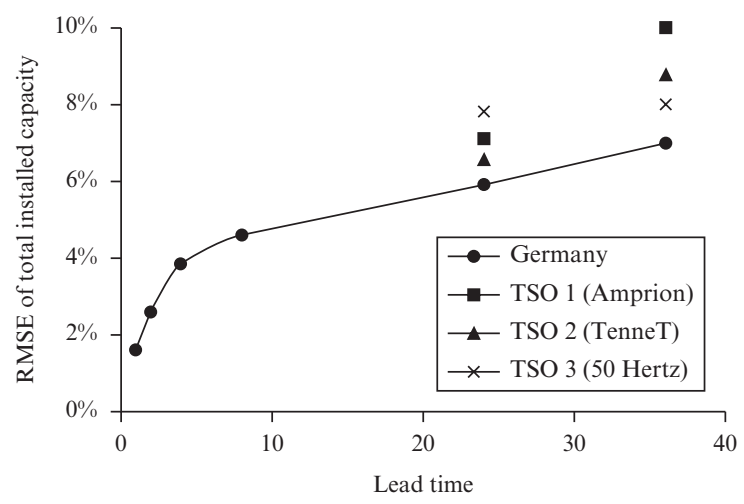

Source: Borggrefe, F. and Neuhoff, K., 2011. 'Balancing and Intraday Market Design: Options for Wind Integration', DIW Discussion Papers 1162, Berlin.

Figure 7.5 Increasing prediction error of wind generation as a function of the forecast horizon for Germany and three transmission zones

flows on transmission networks, including across national borders, as renewable primary sources, especially wind, are available only in certain areas. This has recently led to criticism of the congestion management system implemented in Germany and between Germany and Austria, as it results in large-scale unplanned flows through Poland, the Czech Republic, Slovakia and Hungary, which are not the outcome of any market mechanism. ${ }^{10}$

The pursuit of sustainability objectives is leading to a major change in the logic driving investment decisions in generation capacity. The level of installed generation capacity and its composition are ceasing to be the result of decisions taken by market investors, which bear the corresponding risk. Although with different nuances in different countries, the level of renewable capacity is set by political decisions; in some cases, public planning activity also covers the location of new capacity and the financial support schemes are not technology neutral.

Consistently with a planned approach, the bulk of the risk of investment in renewable generation capacity is placed on the final customers. The widely used feed-in tariff schemes make renewable generators' income independent from the market price of electricity.

In this context competition can still play a role, provided that the planning process is supported by and implemented through auctions. This requires the entity with planning responsibility to act on behalf of consumers as the single buyer of renewable production (and/or capacity). Here a 
tendering system would have a twofold role. The auctions would support planning activity by extracting information on the cost of alternative renewable strategies from the market, and by coordinating transmission and generation capacity expansion. At the same time, auctions would minimise the cost of achieving renewable targets by selecting the lowest-cost providers of renewable generation capacity (and production). Auction-based planning solutions are currently being discussed in some countries, ${ }^{11}$ but we are not aware of any fully fledged planning methodology supported by auctions having been implemented yet.

Incidentally, we note that the politicisation of renewable capacity development, and possibly of nuclear production, has an impact on the level and nature of the risk borne by investors in non-renewable generation capacity. Additional regulatory risk is created by the possibility that politically set renewable targets may change, which could have a dramatic impact on the profitability of non-renewable units. This could lead to higher rates of return being necessary to attract investment in generation capacity, and to further pressure on passing on risk to the customers, typically via capacity support schemes such as those discussed in Chapter 3.

\subsection{SHORT-TERM AND ANCILLARY SERVICE MARKETS}

Renewable energy sources are intermittent and their availability can be accurately predicted only a short time before the time of delivery. As a consequence, the share of total load that needs to be matched by nonrenewable generators is only known with certainty near real time. This means that the production programmes of a large share of the generation capacity may have to be modified as the expectations on renewable production are updated.

In traditional hydropower and thermal systems, major changes in the production schedules set the day before delivery have been relatively rare and have been mainly the response to unexpected outages of large units, while demand prediction errors would typically require limited adjustments. However, with a large share of renewable capacity, large swings in production between different units is becoming a normal feature.

Changes in generators' production programmes need to be matched by economic transactions. In the European context these transactions can take place in the intraday or real-time markets. Intraday market transactions take place between market participants. A wind generator that has sold $100 \mathrm{MW}$ in the day-ahead market and realises a few hours before delivery that it will only be able to produce $70 \mathrm{MW}$, buys the missing 30 


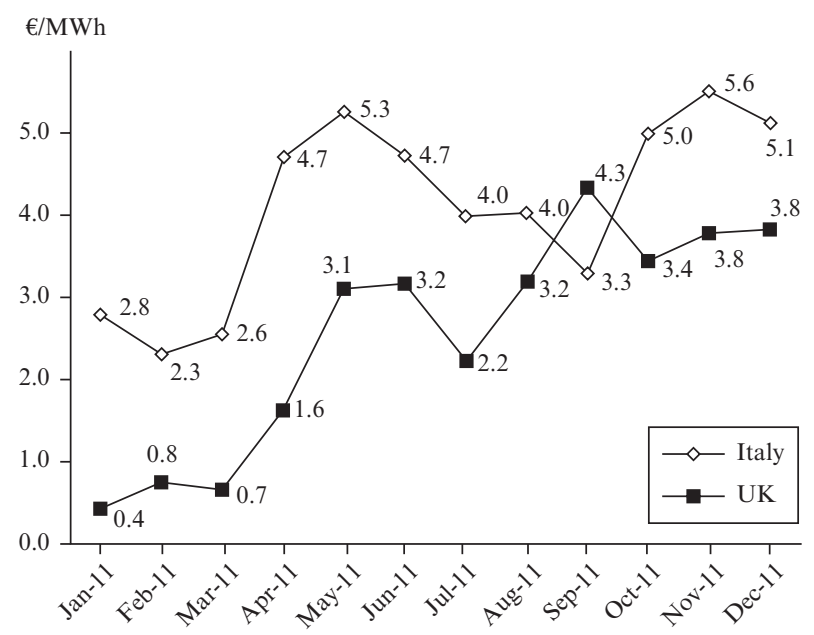

Source: For Italy: Terna. For the UK: National Grid. Monthly Balancing Services Summary.

Figure 7.6 System operators' ancillary services costs in Italy and the UK

MW on the intraday market. Alternatively, the missing $30 \mathrm{MW}$ injections can be supplied by the system operator, which procures it on the balancing market. In this case the wind generator incurs a $30 \mathrm{MW}$ imbalance, which is settled financially with the system operator.

Close to real-time exchanges are increasing in Europe. For example, intraday volumes exchanged in Germany rose from 5.66 TWh in 2009 to $10.3 \mathrm{TWh}$ in 2010 , mainly due to the sale of renewable energy..$^{12}$ In Spain, intraday volumes doubled between 2008 and 2011, in parallel with the development of a large wind generation capacity. ${ }^{13}$ Concerns about increasing system operation costs are also widespread. Figure 7.6 shows the development of system operation costs in Italy and the UK between January 2011 and April 2012.

Moving generation scheduling decisions closer to real time may turn out to be particularly difficult in Europe because of some features of the market design. As we discussed in Chapter 2, in Europe the products traded in day-ahead and intraday timeframes are highly standardised. The standardisation concerns both the location and the time profile of the electricity exchanged. With respect to location, the electricity seller can honour its commitment to deliver by producing at any node of the network within a large control area, which in most cases is the country's borders. The same holds for the buyer. In other words, production 
and consumption at all nodes of a country's transmission network are regarded as identical products.

With respect to the time profile, the seller of certain volume of electricity for delivery during a certain balancing interval - typically a fixed hour or half-hour - can honour its commitment by producing any quantity at any time during that balancing period, as long as the production over the entire balancing interval adds up to the volume sold. Again, the same holds for the buyer. This means that production and consumption with different time patterns within a balancing interval are regarded as identical products.

As a result, market participants exercising the right to deliver the electricity exchanged at any location and with any time profile may violate system security constraints. These are addressed by the system operator through further transactions on the ancillary service markets, which are run independently from the traded markets. When it comes to relieving congestion, however, production at different locations is not a perfect substitute. In the same way, when it comes to offsetting system imbalances on a secondby-second basis, different time patterns of injections are not equivalent. Consequently transactions in the ancillary service markets take place at different prices depending on the location and time profiles of the electricity bought and sold by the system operator. In other words, little or no product standardisation is implemented on the ancillary service markets.

Figure 7.7 illustrates how these features of the European market design impact on the price formation mechanism. Several products that feature complex substitutability and complementarity are traded close to the time of delivery in separate venues. First, market participants exchange standard

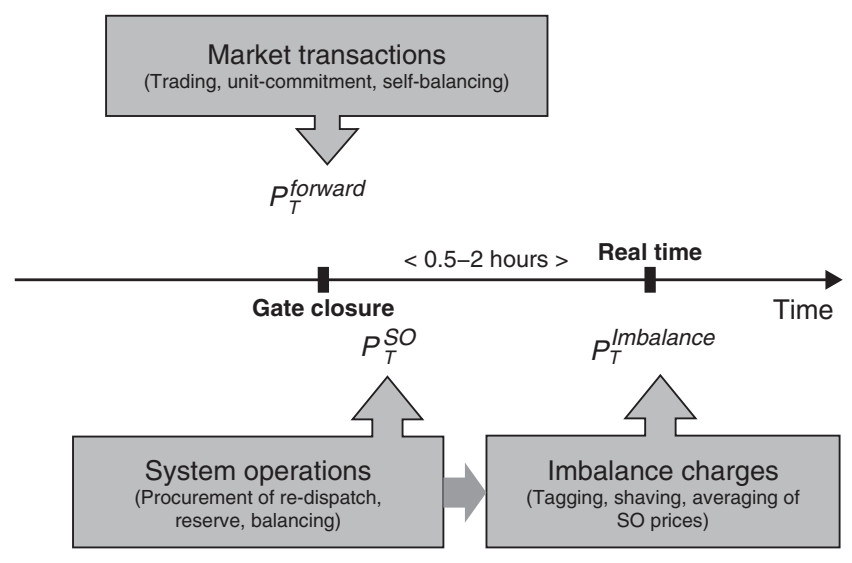

Figure 7.7 Price formation near real time on the European markets 
products on the intraday markets. These exchanges create production and consumption commitments, but leave each market participant free to select where within the control area and with which time pattern within the balancing period production and consumption will take place. A by product of product standardisation is that a unique market clearing price applies for deliveries anywhere in the control area during each balancing period.

Second, after market participants' production and consumption programmes have been notified, in some cases while the intraday market is still running, the system operator enters into transactions on the redispatch and real-time markets in order to ensure that all the security constraints are met. These transactions commit generators to increase or reduce production at specific nodes of the transmission network, and with a specific time pattern during the balancing interval. Consequently, different prices apply to electricity delivered at different network locations and with different time patterns.

Finally, the imbalances (deviations between the production and consumption commitments and actual production and consumption) are settled financially between the market participants and system operator, based on metering data. Imbalance prices are related to but are not the same as the prices paid by the system operator on the real-time market. This is because the imbalance prices must be consistent with the commitments made by market participants, as we argued in Chapter 2, Section 2.1. This requires imbalance prices to be location independent and charged on the net imbalance over the entire balancing period.

The co-existence of multiple products with different degrees of standardisation, negotiated independently on the traded and ancillary service markets, may be viable under certain conditions. If the security-constrained generation dispatch does not depart too far and too frequently from the traded market outcome, the prices of standardised products are representative of real demand and supply conditions and end up driving the bulk of production decisions.

In this case, running the intraday and ancillary service markets separately may not bring about major inefficiencies, since significant differences between the clearing prices of those markets only rarely occur. In addition, if demand and supply conditions are relatively stable, and therefore predictable, market participants are able to exploit any arbitrage opportunities between the different markets and products by implementing suitable bidding strategies. Successful arbitrage across the markets results in consistent clearing prices.

Even the administrative constraints implemented in some markets to reduce system operation costs, such as the right for the system operator to disallow intraday market transactions that would create congestion, may 
cause little harm if they are rarely enforced and if little trading takes place close to real time.

However, the conditions that make segregation of the energy and ancillary service markets viable might not continue to hold as renewable generation production expands. With a large intermittent production capacity, the supply conditions are known only near the time of delivery. More transactions take place close to the real time at prices that may depart significantly from those clearing the day-ahead market.

Furthermore, if the currently observed trends continue in the future, network congestion will become a recurring feature, and the need for fast-response generation capacity will increase. This means that the prices resulting on the re-dispatch and balancing markets - which reflect the real demand and supply conditions - will increasingly depart from the prices of standard products exchanged on the traded markets.

In such a context it may not be possible to achieve consistency between the clearing prices of markets separately run near real time. In addition, the increased need for re-dispatch increases total supply costs, which are ultimately borne by the consumers. This could lead to greater reliance on regulatory and administrative measures aimed at limiting system operation costs, with distortive effects on the prices prevailing in all markets operating close to real time.

The US market design discussed in Section 2.4 can be expected to deal more effectively with the expansion of renewable production. The US standard design is such that the markets for energy and ancillary services are integrated; this ensures the consistency of the prices of all related products. Furthermore, since the same product design is implemented in all timeframes, from the day ahead to real time, the prices that clear the forward and real-time markets differ only to the extent to which the underlying demand and supply conditions have changed. This increases the predictability of the market outcome, and reduces the risk for market participants of missing profitable sales or selling at prices lower than the market-clearing level. Finally, in the US approach, the set of transactions that the market participants can carry out is constrained by the system security constraints. This minimises total supply costs, and makes the introduction of distortive regulatory measures unnecessary.

\subsection{THE RETAIL MARKET}

The Climate and Energy Package requires primary energy use in Europe to be reduced by 20 per cent compared with a baseline scenario. A broad set of energy conservation policies has been adopted 
by the European Union over the last two decades, some of which aim to reduce electricity consumption. ${ }^{14}$ It is generally thought that greater electricity demand response to prices is also important in order to obtain further benefits. If load reduces when the prices increases, production by peaking generators - which involves higher unit consumption and emissions - falls. An additional benefit of peak reduction, other things being equal, is that less generation and possibly less transmission capacity is needed to meet demand.

Currently a large portion of electricity demand is completely price insensitive in the day-ahead to delivery timeframe. This reflects the technical features of the metering systems currently in place. The meters installed at small consumers' premises traditionally record only total withdrawal since the meter was activated, which allows only calculation of the consumer's withdrawal between two readings. At best, small consumers' meters currently record total consumption over long time periods, such as a month. However, it is impossible to record a consumer's withdrawal per hour. When hourly consumption is not known, retail prices cannot directly reflect wholesale market prices, and therefore cannot convey the economic signals of the value of consumption at each time to consumers.

Business consumers are generally metered hourly and can therefore be charged the hourly market price for electricity. However, supply contracts linked to hourly wholesale prices are not common.

Only some major industrial consumers are currently able to respond to real-time prices; these consumers participate in the spot market and, more importantly, the ancillary service markets, as providers of rapid-response demand reduction capabilities.

Interruptible supply contracts allow the system operator to disconnect consumers when system security is threatened. Typically, interruptible service agreements establish the maximum number of disconnections that the consumer can provide per year, the notice period and the maximum length of each curtailment. Despite providing demand-side flexibility, the load reduction implemented through interruptible contracts is not price driven. Rather, interruptible contracts are exercised by the system operator in emergency situations as a last resort reserve before implementing rolling blackouts. Interruptible contracts are typically offered to industrial and large commercial consumers.

In Europe electricity meters with advanced capabilities, or smart meters will have to be deployed for all consumers by $2020 .{ }^{15}$ Recent cost-benefit analyses of the smart meter roll-out to household customers assume that the smart meters will promote a large reduction in electricity consumption, ranging from around 3 per cent (the UK and the Netherlands) ${ }^{16}$ to 6 per cent (Ireland) per year. ${ }^{17}$ However, these predictions about the 
reduction of electricity consumption following the introduction of smart meters appear to be somewhat overoptimistic. It is not clear whether such savings will actually be achieved or what contribution will be provided by the smart metering systems. Concerns have been expressed by the British National Audit Office, for example, which considers that the evidence supporting the assessment of electricity savings carried out in the UK is 'inconclusive'. ${ }^{18}$

The development of electric transport could significantly expand the potential for demand-side response, by placing relatively large electricity storage systems on consumer premises. Assuming that the necessary grid investment is carried out, in 2020 electric vehicles are expected to represent a significant share of the vehicle stock in Europe, ranging from 45 to 74 per cent of passenger car and light-duty vehicles. ${ }^{19}$

Many aspects of the technical, commercial and organisational arrangements enabling small consumers to respond to prices are still undetermined. There may be little willingness among small consumers to spend time and resources setting up the systems to monitor and react to spot and real-time electricity prices. In this case retailers need to mediate the increased involvement of the consumers in the market. The scope of retailing activity is therefore likely to widen. In one possible scenario, retailers will operate as dispatchers of their consumers' controllable load and distributed generation capacity. The consumers will sell their suppliers their capability to vary consumption in exchange for lower supply prices, for example by allowing suppliers to remotely activate or deactivate some appliances under predefined conditions. ${ }^{20}$ Competition among retailers will determine how the value of the demand response is split between them and their clients.

This sketchy description of a possible scenario, where the price-response potential of small electricity consumers is exploited, suggests that its implementation requires large investments in communication systems, electrical appliances and operational and contractual arrangements. Whether the net benefit of a development in that direction is positive ultimately depends on the actual short-term price elasticity of consumption by small clients, which is as yet largely untested. However, given the complexity and scope of the changes involved, very long development and implementation times are to be expected before the full demand-response potential of small consumers can be realised.

Finally, the value of electricity for the consumers is generally regarded as much greater than the market prices in normal conditions. If this assessment turns out to be correct, the demand response will materialise mainly at times of very high prices. Hence, a necessary condition to obtain benefits from the price elasticity of demand is that no regulatory measures 


\section{or market design flaws should prevent prices from rising in situations of scarcity.}

\section{NOTES}

1. The Climate and Energy Package includes several directives and decisions: the Renewable Energy Directive (2009/28/EC), the EU ETS Amending Directive (2009/29/ EC), the Fuel Quality Directive (2009/30/EC), the Carbon Capture and Storage Directive (2009/31/EC), and the Effort Sharing Decision (406/2009/EC). For more details, see http://ec.europa.eu/clima/policies/package/index_en.htm.

2. European Commission, 2009. Directorate-General for Energy. EU Energy Trends to 2030, available at: http://ec.europa.eu/energy/observatory/trends_2030/doc/trends_ to_2030_update_2009.pdf. The reference scenario has been used to collect data on generation. According to the European Commission, the reference scenario assumes that national targets under Directive 2009/28/EC and Decision 2009/406/EC will be achieved in 2020 .

3. European Commission, 2009 (see n. 2).

4. For a survey of renewable generation support schemes, see Meyer, N.I, 2003. 'European Schemes for Promoting Renewables in Liberalised Markets', Energy Policy 31(7), 665-76. A description of the schemes implemented in European countries is provided in Canton, J. and Lindén, A.J., 2010. Support Schemes for Renewable Electricity in the $E U$, European Commission, Directorate-General for Economic and Financial Affairs, available at: http://ec.europa.eu/economy_finance/publications/economic_paper/2010/ pdf/ecp408_en.pdf.

5. ETS system is currently under review and new arrangements are expected to start in 2013. See http://ec.europa.eu/clima/policies/ets/index_en.htm.

6. European Commission, 2011. Proposal for a Regulation of the European Parliament and of the Council on Guidelines for Trans-European Energy Infrastructure, COM/211/658, available at: http://eur-lex.europa.eu/LexUriServ/LexUriServ.do?uri=COM:2011:0658: FIN:EN:PDF.

7. Joint Research Centre of the European Commission, 2011. Smart Grid Projects in Europe: Lessons Learned and Current Developments, available at: http://ses.jrc. ec.europa.eu/sites/ses/files/documents/smart_grid_projects_in_europe.pdf.

8. Electricity consumption in EU27 decreased by about 5 per cent between 2007 and 2009. Eurostat, Energy Database, available at: http://epp.eurostat.ec.europa.eu/portal/page/ portal/energy/data/database.

9. Green, R. and Vasilakos, N., 2009. 'The Long-term Impact of Wind Power on Electricity Prices and Generating Capacity', Department of Economics Discussion Paper no. 11/2009, University of Birmingham, available at: http://www.bhamlive2. bham.ac.uk/Documents/college-social-sciences/business/economics/2010-papers/ economics-papers-2011/economics-papers-2011/11-09.pdf.

10. 'Position of ČEPS, MAVIR, PSE Operator and SEPS Regarding the Issue of Bidding Zones Definition', March 2012, available at: http://www.mavir.hu/c/document_library/ get_file?uuid $=513 \mathrm{~b} 0$ eee-8eb1-405b-85f1-3df85c47237d\&groupId $=10262$.

11. For example, Italy (Legislative Decree no. 28/2011) and the UK (Electricity Market Reform White Paper 2011).

12. Federal Network Agency for Electricity, Gas, Telecommunications, Post and Railways (Bundesnetzagentur). Monitoring Report 2010, available at: http://www.bundesnetzagen tur.de/SharedDocs/Downloads/EN/BNetzA/PressSection/ReportsPublications/2010/ MonitoringReport2010pdf.pdf?_blob=publicationFile.

13. Réd Electrica de España. Informe del sistema eléctrico 2009, 2010, available at: http:// www.ree.es/sistema_electrico/informeSEE.asp. 
14. See 'Energy Savings 2020. How to Triple the Impact of Energy Saving Polices in Europe', available at: http://www.roadmap2050.eu/attachments/files/1EnergySavings2020FullReport.pdf.

15. Directive 2009/72/EC of the European Parliament and of the Council of 13 July 2009 concerning common rules for the internal market in electricity and repealing Directive 2003/54/EC.

16. DECC \& Ofgem, 2011. 'Impact Assessment: Smart Meter Rollout for the Domestic Sector', available at: http://www.decc.gov.uk/assets/decc/11/consultation/ smart-metering-imp-prog/4906-smart-meter-rollout-domestic-ia-response.pdf. For the Netherlands: KEMA, 2010. 'Smart Meters in The Netherlands', available at: http:// www.rijksoverheid.nl/bestanden/documenten-en-publicaties/rapporten/2010/10/25/ smart-meters-in-the-netherlands/10-1193-final-report-smart-metering-ez-draft-v1.pdf.

17. CER, 2011. 'Cost-Benefit Analysis (CBA) for a National Electricity Smart Metering Rollout in Ireland', available at: http://www.cer.ie/GetAttachment. aspx?id=64b7c398-b242-4966-947f-26490b18f117.

18. National Audit Office, 2011. Department of Energy and Climate Change. Preparations for the Roll-out of Smart Meters, available at: http://www.nao.org.uk/publica tions/1012/smart_meters.aspx.

19. European Commission, Directorate General for Mobility and Transport, 2011. Study on Clean Transport System, available at: http://ec.europa.eu/transport/urban/studies/ doc/2011-11-clean-transport-systems.pdf.

20. For an illustration of a recent demand-side management programme, see, for example, Charles River Associates, 2005. Primer on Demand-Side Management, available at: http://siteresources.worldbank.org/INTENERGY/Resources/PrimeronDemandSideManagement.pdf. 